\title{
Recepción e influencia de la literatura hispanoamericana en Corea
}

\author{
Soo-Hyun HwANG \\ Kyung Hee University (Corea del Sur)
}

\begin{abstract}
RESUMEN
A medida que el concepto de "nación" se ha debilitado en estos últimos años, y de forma muy rápida, el límite convencional de la cultura se está desvaneciendo y el mundo se mueve hacia un orden cultural integrado, a través de intercambios constantes entre las culturas, a pesar de las barreras discriminatorias. La literatura, en este sentido, no es una excepción y es necesario discutir la relación entre la literatura coreana y la hispanoamericana desde la perspectiva de la literatura comparativa.

El presente estudio ofrece una mirada más cercana al proceso y a los distintos aspectos del modo en que las obras de los escritores hispanoamericanos han sido aceptadas en Corea del Sur. La literatura hispanoamericana se ha introducido en Corea desde principios del siglo XX y se extendió rápidamente a partir de los ochenta, cuando la controversia literaria del posmodernismo se desató y las obras de Borges y García Márquez fueron presentadas a los lectores coreanos. Sería interesante examinar los aspectos sobre cómo los escritores hispanoamericanos como Neruda, Borges y García Márquez se han integrado en la literatura coreana. En esta etapa, sin embargo, es difícil determinar si su influencia es suficientemente permanente como para convertirse en un linaje, o simplemente se trata de un fenómeno temporal. No obstante, la literatura hispanoamericana seguirá expandiendo interrelaciones crecientes con la coreana más allá de las fronteras, ejerciendo una gran influencia entre sí.
\end{abstract}

Palabras clave: literatura coreana, Pablo Neruda, Jorge Luis Borges, Gabriel García Márquez, literatura comparativa, literatura hispanoamericana.

\section{Acceptance and influence of Latin American literature in Korea}

\begin{abstract}
As the concept "nation" has weakened rapidly in recent years, the conventional boundary of culture is fading away and the world is moving towards an integrated cultural order, through constant exchanges among cultures, despite discriminatory barriers. Literature, in this regard, is no exception and it is necessary to discuss the relationship between Korean literature and Latin American literature from the perspective of comparative literature.

The present study takes a closer look at the process and various aspects of how works of Latin American writers have been accepted in South Korea. Latin American literature has been continuously introduced to Korea since $20^{\text {th }}$ century and spread rapidly after 1980 s when the postmodern literary controversy was unleashed and the works of García Márquez and Borges was introduced to Korean lectors. It would be interesting to look at aspects of
\end{abstract}


how Latin American writers such as Neruda, Borges and García Márquez have been integrated into the Korean literature. At this stage, however, it is difficult to determine if their influence is permanent enough to become a lineage or merely a temporary phenomenon. Nevertheless, Latin American literature will expand growing interrelations with Korean literature beyond boundaries, influencing each other.

Key words: Korean literature, Pablo Neruda, Jorge Luis Borges, Gabriel García Márquez, comparative literature, Latin American literature.

SUMARIO: 1. La historia de aceptación de la literatura hispanoamericana en Corea: 1.1.Transformación en las formas de aceptación según cambios en el entorno de los medios. 1.2. La internacionalidad desterritorializadora de las obras literarias de América Latina en Corea. 2. Obras y autores: 2.1.García Márquez y el realismo mágico en Corea. 2.2. Jorge Luis Borges en la literatura coreana. 2.3. Miradas coreanas sobre Pablo Neruda. 3. Conclusión. 4. Anexo.

La literatura hispanoamericana del siglo XX se independizó de la influencia cultural de Europa, empezó a liderar una corriente literaria propia y a plantear, con ello, nuevas e interesantes cuestiones. Puesto que la literatura hispanoamericana se puso de moda con el boom y el post-boom, dejó de permanecer en la periferia y se convirtió así en un medio generador de discursos literarios importantes. Siguiendo el fenómeno de la globalización que existe en la actualidad y que derrumbó el concepto tradicional de nación, la literatura hispanoamericana está presentando una forma de literatura descentrada y desterritorializadora.

En Corea, la literatura de Hispanoamérica ha estado presente desde el siglo XX y llegó a recibir mucha atención y reconocimiento en la década de los ochenta, momento en que se dieron a conocer autores como Gabriel García Márquez y Jorge Luis Borges con el comienzo de los discursos literarios post-modernistas.

En la actualidad, el público en general puede hablar en un lenguaje abierto, más allá de los confines de la composición y de la lectura impuestos por la sociedad. Este hecho dio lugar al establecimiento del concepto de literatura en tiempos de una nueva composición. La literatura de la época digital llega a tener un efecto dominó en todas las partes del mundo debido a su gran fuerza de velocidad y de franqueza. Hoy en día, la influencia que tuvieron los autores hispanoamericanos sobre los escritores coreanos puede ser, en parte, gracias a la lectura tradicional, pero el hecho de que se haya vuelto más fácil el acceso a sus obras debido a los avances tecnológicos ha jugado un papel principal.

Asimismo, si bien se puede afirmar que la literatura es un producto de la imaginación y de la creatividad artística personales, también es cierto que el medio ambiente contextual ejerce una gran influencia sobre ella. Por consiguiente, el siglo XXI es una época apropiada para que un grupo de autores, expuestos a un nuevo medio ambiente literario, cree la literatura con un concepto totalmente nuevo. 
Como es bien sabido, la literatura es un arte que expresa la complejidad de los sentimientos humanos y la cultura a través de un lenguaje emocional y que confiere más importancia al sentimiento emocional que al reconocimiento intelectual de la política, la economía o la sociedad. Por supuesto, no vamos a menospreciar la corriente intelectualista de la literatura contemporánea (que da importancia a la transmisión de información intelectual).

Este trabajo tratará de estudiar la relación de influencia entre un autor y otro, pero igualmente resultará significativo el hecho de observar la simpatía emocional que los conecta a pesar de la distancia geográfica que los separa. Eso sí, siempre evitaremos que la reacción emocional afecte al trabajo de tal manera que este se base en críticas impresionistas; a tal fin buscaremos la consistencia lógica basándonos en materiales y datos concretos. En cuanto al método empleado, el presente trabajo estudiará el proceso mediante el cual los autores hispanoamericanos fueron acogidos en Corea, y su influencia en el mundo literario de este país asiático.

\section{La historia de aceptación de la literatura hispanoamericana en Corea. Transformación en las formas de aceptación según cambios en el entorno de los medios}

En el estudio de la literatura es indispensable el interés acerca del autor, ya que es el sujeto creativo. De la misma forma es indispensable comprender la realidad y la historia de la obra y conocer en qué entorno y por qué motivo la escribió el autor. Asimismo hay que estudiar en qué aspectos ha influido dicha creación literaria en los lectores y la reacción que mostraron éstos. ¿Cómo podríamos definir la relación entre los autores hispanoamericanos y los lectores coreanos? Hoy en día el lector no está limitado ni por el tiempo ni por el espacio. Una obra de un autor popular es traducida a varias lenguas inmediatamente después de su publicación y es posible leerla por e-book en los Tablet PCs. La literatura se encuentra con nuevos lectores más allá del tiempo y del espacio y se otorga con un nuevo significado. Estamos hablando de nuevos encuentros muy atractivos.

Es interesante observar de qué forma se han disuelto y han influido los autores hispanoamericanos como Neruda, Borges y García Márquez en las obras literarias coreanas. Pero resulta difícil de definir en estos momentos si esa influencia es permanente como para generar un linaje literario o se trata solamente de un fenómeno temporal. De todas formas, están siendo traducidas y presentadas continuamente obras hispanoamericanas en Corea, y es un hecho innegable que las creaciones literarias de los autores mencionados más arriba tienen una gran influencia en la composición de los autores jóvenes en la actualidad. Es cierto que las obras de los escritores coreanos bajo la influencia del realismo mágico de García Márquez y las de los autores influidos por lo fantástico de Borges muestran diferentes aspectos y que no tienen la misma influencia unas que otras. Asimismo, 
al igual que la diferencia de sentimientos en cada país hispanoamericano, la literatura de cada una de estas naciones utiliza su propio lenguaje literario, con lo cual sería más idóneo afirmar que cada obra coreana ha recibido la influencia de la forma literaria propia de cada autor, en lugar de hablar de la influencia de la literatura hispanoamericana. Para evitar cualquier tipo de disputa, en este trabajo desarrollaremos el tema basándonos en la universalidad de la literatura hispanoamericana.

\section{La internacionalidad desterritorializadora de las obras literarias de América Latina en Corea}

La riqueza de la literatura hispanoamericana se dio a conocer en el mundo gracias a la propagación de la poesía del modernismo y de los logros de la literatura del Boom.

Es bien conocido el hecho de que los avances literarios de Rubén Darío contribuyeron a que se diera a conocer la literatura hispanoamericana en el mundo y que sus obras influyeron en los autores de la Generación del 98 y en los poetas de la Generación del 27 de España. Sin embargo, pese a su valor literario, la literatura de Darío no llegó a conocerse bien entre los lectores coreanos. Las obras del nicaragüense fueron presentadas de vez en cuando por los hispanistas coreanos. En invierno de 2012 se publicó por primera vez en dicho país asiático el primer poemario en forma de antología (Kim 2012).

Después del modernismo fueron los autores del Boom los que desvelaron el valor de la literatura hispanoamericana en el mundo. La literatura de los países hispanoamericanos se conoció en el mundo como la de América Latina en su totalidad y no como la de un país específico a causa de la 'novela del Boom' en los años sesenta. La novela del Boom guió a la literatura hispanoamericana, que hasta entonces era una literatura del tercer mundo en las periferias, al núcleo de atención mundial; además, lideró el auge de la literatura hispanoamericana en el ámbito literario de todo el mundo. En Corea, los autores del Boom se dieron a conocer principalmente en torno a las obras literarias de los autores ganadores del premio Nobel. Gabriel García Márquez fue el primero de los autores del Boom en ser presentado en Corea y cuyas obras fueron traducidas al coreano.

\section{Obras y autores.}

\section{García Márquez y el realismo mágico en Corea}

El concepto de realismo mágico se expandió de forma amplia en Corea cuando Gabriel García Márquez ganó el premio Nobel de literatura con una obra que tiene como eje su novela Cien años de soledad (1967. Traducida al coreano en 1977). Los lectores coreanos la interpretaban de forma mágica y mitológica, pero también resaltaban el realismo poniéndola en comparación con la situación política de Corea en aquella época. Ciertamente, el realismo mágico ha generado mucha polémica en 
cuanto al uso del término y la definición de categoría. Muchos investigadores han planteado el peligro de usos indiscriminados de dicho término. La obra de García Márquez fue una sorpresa agradable para el mundo literario tanto por la controversia generada por el término como por lo novedoso y lo maravilloso de la obra, ya que en aquel entonces estaba de moda el criticar la situación política de entonces a través de la poesía con metáforas y sátiras. Era un período de dictadura militar y la novela del realismo, que representa la injusticia y lo absurdo de la sociedad de forma realista, muchas veces se encontraba limitada al exponer la realidad debido a la misma situación política. Por tanto, la novela difícilmente contenía los hechos reales que criticaban el sistema dictatorial, y los autores que, más allá de reflejar la realidad objetiva en general, buscaban darle una forma más cercana a la realidad verdadera de forma literaria, encontraron una metodología literaria diferente cuando conocieron el mundo literario de García Márquez. Es decir, llegaron a atravesar los límites que la literatura del realismo existente no podía cruzar y buscaron una posibilidad estética nueva a través de la figuración literaria de la vida del pueblo. Fue asombroso encontrar esta posibilidad de la figuración literaria a través de un cambio químico, y no de la coincidencia directa y completa entre el objeto descrito y el objeto real.

La influencia que tuvo García Márquez sobre la literatura coreana es fácil de encontrar; en especial, a finales de los años noventa y a principios del siglo XXI aparecen obras que sugieren su influencia. En las novelas coreanas se pueden encontrar rasgos de las novelas hispanoamericanas en cuanto a su contenido argumental o a la técnica utilizada de realismo mágico o lo real maravilloso. Ejemplos de ello son La ballena ${ }^{1}$ de Myung-gwan Chun y El hostal Cien Años ${ }^{2}$ de Chul-woo Im. Como sugiere el título de esta última novela, Chul-woo Im utiliza el tiempo 'cien años' y presenta un espacio ficticio llamado 'Yeongdo' (Im 2004: 9) equivalente a Macondo, escenario principal de Cien años de soledad. La novela de Chul-woo Im intentó crear una isla ficticia que, en su forma original, es "un pueblo no demasiado grande, tampoco demasiado pequeño, con una apariencia pacífica, pero por dentro ardiente como magma; el espacio que sueña es una aldea ficticia como el 'Condado Yoknapatawpha' creado por William Folkner o 'Macondo' por García Márquez"3 (Im 2004b: 67). Como se puede comprobar en estas palabras del propio autor, Im intentaba representar a Macondo, el espacio materializado con éxito en Cien años de soledad por Gabo, en el espacio de su novela. Intentó dar una forma literaria a la historia contemporánea de Corea a través de 'Yeongdo' en su novela El hostal Cien Años. 'Yeongdo' en coreano significa 'isla de sombra', con lo

\footnotetext{
${ }^{1}$ El título original en coreano es Gorae.

${ }^{2}$ El título original en coreano es Beknyun Yeogwan.

${ }^{3}$ Traducción mía. Todas las traducciones del coreano al español que aparecen en este trabajo son traducción mía.
} 
cual el espacio en sí puede ser una sombra, una ilusión ficticia. Im empleó el estilo y la retórica a lo García Márquez en un espacio donde se cruzan la realidad y la ficción. Cuando muere la anciana Seolbunne, sopla un viento fuerte durante diez días y por tanto "en el patio trasero del Hostal Cien Años, los viejos árboles fueron arrancados y tirados en el suelo. De los huecos dejados por estos árboles salieron arrastrándose miles de ranas y cientos de serpientes simultáneamente" (Im 2004a: 66). Además "en pleno invierno dieron los cerezos su flor en todas las ramas". Esa misma noche, al soplar el viento, "los pétalos volaron hacia el vacío y los cerezos se quedaron escuálidos en una noche" (Im 2004a: 67). Esta escena puede ser comparada con la lluvia de flores que cae cuando muere José Arcadio Buendía en Cien años de soledad. ¿Será que el mundo humano y el mundo natural se corresponden? Al igual que el tiempo en Cien años de soledad se libra de los límites de la crónica y crea un nuevo significado del tiempo, el autor Im reconoce que la muerte y el nacimiento no son dos mundos separados por dicotomía y advierte que "un objeto y su sombra son uno como la vida y la muerte son un solo cuerpo" (Im 2004a: 343). La concepción oriental sobre la relación entre el hombre y la naturaleza o sobre la vida y la muerte se podría interpretar como un intento de injertar el realismo mágico a lo coreano a través del estilo de García Márquez. Es decir, al igual que el autor colombiano combinaba las mitologías y leyendas del caribe con la realidad de su tiempo, se podría considerar que Chul-woo Im intentó combinar el chamanismo coreano con la realidad de su época.

El realismo mágico presenta sucesiones de acontecimientos maravillosos y aumenta sistemáticamente los elementos mágicos a partir de la realidad descrita, como se puede comprobar en Cien años de soledad de García Márquez. Podemos encontrar otros autores que intentaron el realismo mágico a lo coreano, además del ya mencionado Chul-woo Im. El autor Myung-gwan Chun, en su obra La ballena, cuenta una historia que atraviesa la época sombría de la historia contemporánea de Corea desde la colonización japonesa hasta estos días gobernados por el 'general'. La estructura narrativa de la obra tiene cierto parecido con la de García Márquez; en ésta, la narración comienza con el asesinato accidental de José Arcadio Buendía, mientras que en la de Chun la historia se origina a causa de la venganza accidental de la vieja de una taberna cuando era joven. Cien años de soledad cuenta la historia de la familia Buendía a lo largo de cien años; La ballena narra la historia de la vieja de la taberna y la de otra familia de tres generaciones de abuela, madre e hija. En Cien años de soledad encontramos un espacio ficticio llamado Macondo donde ocurren los acontecimientos, mientras que en La ballena se suceden en Pyungdae, otro lugar ficticio. Este contiene la historia contemporánea de Corea: la independencia, la guerra civil, la dictadura y el desarrollo económico a una velocidad tremenda. Asimismo nos realiza una pregunta sobre el significado ontológico por medio de la prosperidad y el desastre de Pyungdae, que aparece como fondo literario (Jeon 2005: 311). No obstante, este parecido de la configuración temporal-espacial y de la estructura de la narrativa no es prueba 
suficiente de que La ballena tenga características de realismo mágico. Lo que le confiere el carácter de realismo mágico no es el tiempo o el espacio simbólico, sino la introducción de elementos supernaturales en el espacio natural, dando lugar a la transformación mitológica del mundo cotidiano (Mayans 1996: 246). El autor Chun nos dice: "la he escrito para llenar nuestro siglo pasado con historias que corren por el mundo" (Ryoo 2004: 446). Realmente, su obra cuenta las historias de personajes marginados a lo largo del proceso de modernización de Corea y contiene escenas en las que coexisten y conversan los muertos y los vivos. La relación que tiene esta sobrenaturalidad con los elementos realistas detecta el misterio inmanente en el otro lado de los objetos y es la prueba de su semejanza con la obra de García Márquez.

En los años ochenta, el grupo de escritores nacionalistas de Corea discutía sobre el realismo de García Márquez, criticando que no abarcaba la dura vida del pueblo en su totalidad y que aspiraba elevarse a la élite de la literatura dominante. Pero el hecho de que la literatura hispanoamericana se situara en el centro de la postmodernidad y se hubiera introducido en Corea, generando debates y polémicas, fue muy productivo. Como consecuencia, podemos presenciar hoy en día autores coreanos que han recibido la influencia directa de Gabriel García Márquez.

\section{Jorge Luis Borges en la literatura coreana}

Por otro lado, a finales del siglo XX Borges se convirtió en el origen de la teoría de la literatura contemporánea en medio de la controversia post-modernista. Borges, que marcó un hito en la historia intelectual del siglo XX, se dio a conocer en Corea por medio de los hispanistas o gracias a los especialistas en la literatura inglesa o americana. Al principio fue discutido desde la perspectiva de la teoría literaria, pero luego pasó a ejercer su gran influencia en los ámbitos de la cultura, la filosofía, la estética y la literatura.

En Corea empezaron a aparecer autores que seguían la composición 'a lo Borges'. Para comprender esta situación, es necesario comentar la aceptación de la literatura fantástica en el mundo literario de Corea. Fue a mediados de los años noventa cuando empezó a discutirse la literatura fantástica en dicho país. Se puede comprender como un código que simbolizaba la desideologización y la diversidad cultural del mundo literario coreano a finales del siglo XX. Se convirtió en uno de los movimientos que buscaba nuevas formas de composición en la época en la que el foco pasó a posicionarse de "la revolución al movimiento, de la práctica al deseo, del progresismo al pluralismo, del nacionalismo a la globalización, de Marx a Foucault y a Baudrillard" (Jang 2000: 433-434).

Además de la literatura fantástica, Borges tuvo mucha influencia en varios campos, incluida la forma de escribir, con lo cual la expresión 'a lo Borges' es algo muy familiar en el mundo crítico de Corea. Byeong-sun Song, traductor y crítico literario, escribe lo siguiente: "si leemos las novelas coreanas recientes, en los años noventa los escritores con una nueva forma de expresión y una nueva concepción literaria están obsesionados con el fantasma llamado Borges" (Song 2002: 162). Del 
mundo literario de Corea los autores más influenciados por Borges son Yeon-soo Kim, Hyung-seo Park, Kyoung-ah Song, Seung-woo Lee etc.

El autor Yeon-soo Kim explotó un territorio único llamado 'composición de novelas como una búsqueda del texto original'. Específicamente el cuento titulado "El incidente complot de la biblioteca Gongyajang" (Kim 2000) cuenta la historia de un bibliotecario que asesina al director de la biblioteca llamado Gongyajang, que en realidad es un ladrón de libros que los confina.

"El incidente complot de la biblioteca Gongyajang" es una obra que se escribió empleando técnicas experimentales con motivos de "La biblioteca de Babel" y de "Funes el memorioso". "La biblioteca de Babel" y "Funes el memorioso" se convierten en la novela de Kim en la 'biblioteca' y 'Gonyajang'. Gongyajang es un genio que se sabe de memoria todos los libros de su biblioteca, y podría ser considerado como una parodia de Funes. El autor comenta que tomó prestado el motivo de la novela de dos de las obras de Borges:

Solía recordar la novela que escribió Borges como Funes el memorioso. El pasaje más impresionante de la novela es el siguiente: "ahora que mis ojos casi no pueden descifrar lo que escribo, me preparo a morir a unas pocas leguas del hexágono en que nací."

Igual que Borges, Gongyajang creyó que podía meter todos los libros del mundo en la biblioteca si tan sólo hubiese espacio suficiente para construirla. Como las combinaciones de las letras son limitadas, el deber de un bibliotecario es ir dividiendo infinitamente el espacio para guardar los libros (Kim 2000: 16).

En la obra que le sigue, Goodbye Yi Sang, (Kim 2001) el mismo autor crea la biografía falsa de un poeta real llamado Yi Sang, tomando prestado el método utilizado en "Pierre Menard, autor del Quijote". Es un ejemplo de prueba de la intertextualidad, prototipo de la composición a lo Borges, donde se anula la diferenciación entre los datos reales y los datos imaginarios. Otro autor coreano, llamado Hyung-seo Park, parece parodiar los cuentos "Examen de la obra de Herbert Quain", recogido en la obra borgiana de Ficciones y "Biografía de Tadeo Isidoro Cruz (1829-1874)" en El Aleph, con su cuento "Estudio sobre la obscenidad de El huésped y mi madre", recogido en su colección Ficciones de medianoche. (Park 2006) Además, el autor manifiesta de forma directa la postura del narrador utilizando el método de la cita falsa, es decir, poniendo notas al pie de una obra inexistente de Borges. Si recordamos el hecho de que Borges prefería citar libros imaginarios, las notas constituyen un elemento importante para la composición de Ficciones.

Kyoung-ah Song, autora influenciada por Borges, intentó adoptar una forma nueva de escribir, a diferencia de los autores tradicionales que observaban de forma microscópica el entorno social o las experiencias en el campo de la vida. Pertenece a una nueva generación acostumbrada a utilizar el ordenador adaptándose al cambio 
de medios y, efectivamente, empezó a publicar sus obras en una tertulia literaria en Internet. La citada autora pretende elaborar un nuevo significado del 'libro' a través del encuentro de ordenadores y libros. En su obra Libro (Song 1996) intenta escribir a lo Borges, borrando e integrando los límites entre la realidad y la ficción.

Libros, innumerables libros. Escribiré libros sobre mi vida. Libros falsificados, copias, libros mal encuadernados, dos libros que son idénticos hasta la primera mitad pero que son distintos en la segunda parte, libros que tratan el mismo tema pero con diferentes estilos, libros con una hoja diferente, libros con una palabra diferente, libros con una letra diferente, libros de diferentes ediciones, libros con diferentes encuadernaciones, escribiré innumerables libros. Así haré que no puedan diferenciar entre el verdadero libro y el falso (Song 1996: 34).

Aquí el libro no genera un significado fijo e inmortal, sino que es algo dinámico que se crea en relaciones variadas y que genera correspondencias que flotan, terminan y renacen. Se parece a lo que Borges quiso contener en el libro, es decir, la creación de un mundo imaginario de modo dinámico, más allá del mundo real, o a las palabras de Roland Barthes en De la obra al texto (1971), que enfatizan la autonomía del texto y que afirman que la intertextualidad pone en relación el texto con los demás textos con los que estable relaciones de significado. Hemos visto que leer las obras de Borges es una búsqueda del laberinto y un viaje alegre por acercarse a la sabiduría conocida o desconocida del mundo. Un crítico dijo una vez que el español nunca desaparecerá siempre que existan las obras de Borges. Lo mismo podríamos decir nosotros: siempre aparecerán autores coreanos influidos por Borges si existen las obras de Borges. Todo ello debido a la inmortalidad de su escritura, que va más allá de los límites del tiempo y del espacio, su inmenso conocimiento enciclopédico y su imaginación sin fronteras. El hecho de que las teorías del post-estructuralismo y del post-modernismo, que provocaron acalorados debates a finales del siglo XX, tienen su origen en Borges es prueba de ello.

\section{Miradas coreanas sobre Pablo Neruda}

Pablo Neruda, poeta chileno que ganó el premio Nobel de literatura en 1971, es un nombre muy familiar para el lector coreano. El poeta con apariencia modesta que enseñaba poesía a un cartero de pueblo en la película titulada Il Postino, el poeta del pueblo que cantaba a América Latina en la cima del Machu Picchu y el poeta que cantaba el amor ardiente en Veinte poemas de amor y una canción desesperada. Todas estas imágenes describen a Neruda en Corea.

Se puede decir que Neruda es uno de los ganadores de premio Nobel más querido por los lectores coreanos. Los libros de texto colegiales contienen sus poemas, entre ellos, "La poesía" y "Puedo escribir los versos más tristes esta noche"; hace poco el muro exterior de un edificio colgaba una pancarta con un 
pasaje de uno de sus poemas. Pero la poesía de Neruda "se recibió en Corea de forma distorsionada, engranada con la realidad del mundo literario de Corea que había estado barrida por tantas cuestiones ideológicas como la situación política de Corea, la controversia de literatura pura/participación en la política o la del realismo/modernismo, etc." (Kim 2006: 210) En otras palabras, a veces se definió como el poeta del pueblo, mientras que otras veces se hablaba de él como el poeta del amor.

Como es bien sabido, el autor, durante el tiempo que permaneció en España como diplomático, observó la guerra civil española y se encaminó hacia el socialismo en contra del fascismo. En 1949 visitó la Unión Soviética y en 1950 recibió, junto con Pablo Picasso, el Premio Internacional de la Paz por su poema "Que despierte el leñador" (Neruda 1996: 466). A partir de entonces actuó como miembro del jurado de Premio Lenin de la Paz. Neruda fue un intelectual que siguió el camino izquierdista progresista en la época de la Guerra Fría. Corea también sufrió la guerra civil desde 1950 hasta 1953. Fue en los años cincuenta cuando Pablo Neruda fue presentado por primera vez en Corea. Y fue primero en Corea del norte, país comunista, donde se dieron a conocer las obras de Neruda. Autores como Tae-jun Lee, Gi-young Lee, Sul-ya Han, que residían en Corea del norte, fueron los que introdujeron los poemas de Neruda. En especial, Gi-young Lee, poeta que se había marchado del sur, se reunió con Neruda en el año 1952 y dijo estas palabras del escritor chileno: "Él es también un luchador revolucionario que clava el corazón del imperialismo americano con un lenguaje poético agudo y despiadado. Es muy conocido como poeta revolucionario entre los autores progresistas del mundo" (Kim 2006: 212). De este modo, Neruda fue un poeta de mucho interés para los poetas izquierdistas de los años cincuenta. Sin embargo, a partir de los años sesenta, en el sur de Corea también se dieron a conocer las obras de Neruda. Fue el poeta Su-young Kim el que introdujo en serio la poesía del chileno en el mundo literario de los sesenta en Corea del sur. Kim era un poeta que ponía énfasis en la práctica y participación social basada en la comprensión de la situación sociopolítica del tiempo, con lo cual se identificaba en parte con el mundo poético de Neruda.

El premio Nobel de literatura que ganó Neruda en 1971 actuó de catalizador para que su poesía se conociera ampliamente en Corea. El poeta Nam-ju Kim, que escribía poemas de resistencia, le dedicó una ferviente alabanza. En aquellos tiempos estaba encarcelado como preso político, pero leía y traducía la poesía de Neruda en japonés y en inglés, e incluso se mostró tan apasionado como para estudiar el español a fin de poder comprenderla en su lengua original. Presentó la vida y el mundo literario de Neruda y citó al poeta chileno como uno de los autores que más le habían influido. Confesó en uno de sus escritos: "Tengo gran interés en las obras literarias que describen la vida y la lucha de la clase trabajadora, que se ve obligada a sufrir una vida inhumana bajo la opresión y explotación de la clase dominante". (Kim 1989:174) Además, Nam-ju Kim publicó un poemario traducido 
Para ser leído por la mañana y por la noche (1988) con 32 poemas de Neruda y otros de Heinrich Heine y Bertolt Brecht, traducidos por él mismo durante los nueve años de encarcelamiento. La mayoría de los poemas traducidos pertenecen a Tercera residencia y Canto general. Asimismo, la poesía de Neruda que se dio a conocer en Corea en los años setenta y ochenta, en su mayoría, eran poemas revolucionarios que expresaban el sentimiento del pueblo, como reflejo de la situación política de la Corea de entonces. El hecho de que muchos lectores coreanos consideraran a Neruda como un poeta del pueblo se debe a su experiencia de haber leído sus poemas en aquellos tiempos.

No obstante, pasados los años ochenta, una época en alta mar, en los años noventa la presentación de Neruda se realizó de forma más variada, quizás en parte por el cambio de ambiente político en Corea. Este país dejó de estar bajo el mandato de una dictadura militar y empezaba a gozar de un ambiente social más democratizado. A partir de entonces se han dado a conocer poemas variados como los de Veinte poemas de amor y una canción desesperada, lo que sirvió de medio para mejorar la comprensión sistemática e integral del mundo poético de Neruda ${ }^{4}$. Si bien hasta los años ochenta Pablo Neruda fue considerado como poeta del pueblo, a partir de la década de los noventa se dio a conocer como el vate que cantó el amor, la naturaleza, la vida cotidiana, y que ensayó la técnica surrealista con su poesía.

Los poemas de Neruda fueron traducidos al coreano por partes durante un tiempo hasta que Hyun-jong Jung y Hyeon-kyun Kim, especialistas en el poeta chileno, tradujeran una gran mayoría de ellos.

En el discurso pronunciado por Neruda con ocasión de la entrega del Premio Nobel de Literatura dijo: "Yo vengo de una oscura provincia, de un país separado de todos los otros por la tajante geografía. Fui el más abandonado de los poetas y mi poesía fue regional, dolorosa y lluviosa". Paradójicamente fue él quien acarició a un pueblo marginado en las periferias del oriente lejano. ¿No será por esta razón que la poesía de Neruda fluye y calienta el corazón de los coreanos?

\section{Conclusión}

Hoy en día, el concepto de la nación se ha debilitado con rapidez y destaca el fenómeno deslimitador. Este fenómeno derrumba, pues, los límites culturales o el nacionalismo existentes. En el siglo XXI las obras literarias que cuentan la

${ }^{4}$ Podemos citar al poeta-traductor Hyun-jong Jung como uno de los personajes más importantes que presentó a Pablo Neruda en los años noventa. Le otorgaron la medalla conmemorativa de Neruda en el centenario de nacimiento del poeta chileno en 2004, en reconocimiento por sus constantes labores de introducción de la poesía del poeta chileno en Corea. 
universalidad de la vida humana se expanden con gran rapidez a través de medios de comunicación como Internet. La evolución de la tecnología digital destaca la importancia de la conexión más que de la posesión y el almacenamiento de los datos. De esta manera, se ofrece un entorno en el que las comunicaciones y la influencia recíproca entre autor-autor y autor-lector se llevan a cabo de una forma mucho más variada. Por consiguiente, resulta difícil hablar de la identidad de la literatura de un país de modo tradicional. La literatura hispanoamericana del siglo XXI expande su territorio a través de la globalización literaria y la asimilación cultural. Se puede observar que, últimamente, el interés por los autores hispanoamericanos y sus obras literarias está creciendo entre los autores coreanos. Si durante los años sesenta y setenta se introducía la literatura hispanoamericana en torno a la poesía, en los setenta y en los ochenta se solía enfocar en la literatura del pueblo desde el punto de vista de compromiso social. Esta tendencia se transformó conforme la sociedad coreana se liberaba del sistema dictatorial, convirtiéndose en algo más democrático. A partir de los años noventa la literatura hispanoamericana se ha presentado en Corea a través de varios géneros literarios. En los últimos años se han traducido y presentado las obras de diversos autores hispanoamericanos, desde las obras del género del Boom hasta las obras de Vargas Llosa o de Bolaño. Un hecho alentador es que últimamente se están realizando trabajos sobre la literatura auténtica, como la de Bolaño. En realidad, Bolaño es uno de los autores más estudiados en la actualidad entre los hispanistas coreanos y hace poco la Revista Iberoamericana de la Universidad Nacional de Seúl publicó artículos sobre este autor chileno en especial.

Esta presentación e introducción de la literatura hispanoamericana está ejerciendo una gran influencia sobre la redacción de los autores coreanos, y los críticos expresan su asombro y admiración ante la creatividad y la imaginación de la literatura hispanoamericana. Sin embargo, hay que reconocer que la presentación de las obras hispanoamericanas se ha hecho en torno a la novela, con lo cual son relativamente escasas la traducción o la presentación de la poesía. ${ }^{5}$ Es una lástima que aún no haya sido traducida al coreano la poesía de Vicente Huidobro, el autor más representativo de la vanguardia hispanoamericana. Este hecho refleja la realidad de Corea, donde la poesía se encuentra marginada. En el futuro, el mundo editorial debería intentar presentar y publicar los poemas de calidad.

En la actualidad, las escuelas europeas o los discursos occidentales, que habían gozado de poder durante largo tiempo, han perdido su hegemonía, dando lugar a un nuevo horizonte literario. Gracias a esto, entre los autores coreanos se da una nueva forma de boom de literatura hispanoamericana. Reconociendo que el pensamiento nómada es el linaje que conecta a Corea, que está en el Lejano Oriente, con

${ }^{5}$ La lista de las obras traducidas al coreano adjunta en el Anexo hace constar que, efectivamente, la mayoría de las traducciones al coreano se ha hecho en torno a la novela. 
América Latina, la literatura hispanoamericana tendrá una relación recíproca que atraviesa los límites para intercambiar su influencia con la literatura coreana. Más allá de las imágenes del realismo mágico y de lo fantástico, nos anticipamos a un mutuo préstamo de una literatura nueva y emocionante entre la literatura hispanoamericana y la de Corea.

\section{BIBLIOGRAFÍA}

BLÜHER, Karl Alfred y Alfonso DE TORO (eds.).

1995 Jorge Luis Borges: Variaciones interpretativas sobre sus procedimientos literarios y bases epistemológicas. Madrid: Iberoamericana.

EARLE, Peter (ed.).

1981 Gabriel García Márquez. Madrid: Taurus.

GARCÍA MÁRQUEZ, Gabriel.

1995 Cien años de soledad. Ed. Jacques Joset. Madrid: Cátedra.

IM, Chul-woo.

2004a El hostal Cien años. Seúl: Hangyore Sinmun.

2004b "Chilseonnyeoju”. Munhak.Pan. Invierno. Seúl, 67.

JANG, Suk-joo.

2000 Exploración de la literatura coreana del siglo XX. 1989-2000. Seúl: Sigongsa.

JEON, Yong-gab.

2005 "El realismo mágico en La Ballena, de Chun, Myeong-Kwan: en torno al modo y la función de los elementos sobrenaturales", Estudios Hispánicos, n 36 : 303-322.

KIM, Hyeon-kyun.

2006 "Pablo Neruda en Corea", Estudios hispánicos, no 40: 207-225.

2012 Antología poética de Rubén Dario. Seúl: Geulnurim.

KIM, Nam-ju.

1989 Armas de amor. Seúl: Changbi.

KIM, Yeon-soo.

2000 "El incidente complot de la biblioteca Gongyajang", en Veinte años. Seúl: Munhak Dongne.

2001 Goodbye Yi Sang. Seúl: Munhak Dongne.

KIM, Young-moo.

1996 "Pablo Neruda and Today's Korean Poetry", Korea Journal. Seúl, vol. 36.

MAYANS NATAL, María Jesús.

1996 "La expresión poética de la muerte en Cien años de soledad", en Hernández de López (ed.), Narrativa hispanoamericana 
contemporánea: entre la vanguardia y el posboom. Madrid: Pliegos.

NERUDA, Pablo.

1992 Canto general. Ed. Enrico Mario Santí. Madrid: Cátedra.

1995 Odas elementales. Ed. Jaime Concha. Madrid: Cátedra.

1996 Confieso que he vivido. Barcelona: Plaza \& Janés:

PARK, Hyung-seo.

2006 Ficciones de medianoche. Seúl: Munhakgwa Jisung.

RYOO, Bo-sun.

2004 "Entrevista del autor premiado: historia, o el futuro de la novela", en La ballena, por Myung Kwan Chun. Seúl: Munhak Dongne.

SONG, Byeong-sun.

2002 Entregarse al laberinto de Borges. Seúl: Chaegi Innun Maeul.

SoNG, Kyoung-ah.

1996 Libro. Seúl: Mineumsa.

\section{ANEXO}

Autores hispanoamericanos cuyas obras han sido traducidas y publicadas en Corea

\section{García Márquez, Gabriel}

1977 Cien años de soledad. Trad. Jung-hyo Ahn, Munhak Sasangsa

1986

1988 . Trad. Il-sang Park, Semyung Munhwasa

1989 . Trad. Sung-ho Chung, Donga

1992 . Trad. Song-hee Lee, Baeksang

1993 . Trad. Ga-hyeong Lee, Ed. Haseo

1994 . Trad. Su-yeon Park, Ed. Hyewon

1994 . Trad. Dong-jin Shin, Chungmoksa

1995 Trad. Ho Choi, Hongshin Munhwasa

1996 . Trad. Sang-gyo Chung, Ed. Yeomyung

2000 Trad. Ho-jun Lim, Koryeowon Media

2006 Trad. Gu-ho Cho, Mineumsa

1977 El coronel no tiene quien le escriba. Trad. Bo-up Hong, Mineumsa 1982 La hojarasca. Trad. Jong-gwan Lee, Jimunsa

1983 Crónica de una muerte anunciada. Trad. Bong-hee Cha, Saemteosa 1983 . Trad. Jung-hwa Kim, Jungeumsa

1996 . Trad. Chang-hwan Kim, Univ. Ulsan

2008 . Trad. Gu-ho Cho, Mineumsa

1987 La increible y triste historia de la cándida Eréndira y de su abuela desalmadad. Trad. Kachi 
1988 El amor en los tiempos del cólera. Trad. Byung-wook Kim, Neulpureun Namu

2004 . Trad. Byeong-sun Song, Mineumsa

1991 Cuando era feliz e indocumentado. Trad. Sung-ho Chung, Haneul

1991 El general en su laberinto. Trad. I-bae Kim, Instituto de Investigación Chunggye

1991 La mujer que llegaba a las seis. Trad. Yong-tae Min, Munhak Sasangsa

1994 La mala hora. Trad. Jae-nam Kim, Jungmin

1995 Del amor y otros demonios. Trad. Jun Kim, Hanteut

2008 . Trad. Suk-gyun Woo, Mineumsa

1995 Doce cuentos peregrinos. Trad. Hyo-suk Han, Hannarae

1997 Me alquilo para soñar. Trad. Byeong-sun Song, Haneul Yeonmot

1999 Noticia de un secuestro. Trad. Mi-sun Kwon, Mineumsa

2000 La aventura de Miguel Littín clandestino en Chile. Trad. Gu-ho Cho, Crepas

2003 La luz es como el agua. Trad. Byeong-sun Song, Joeun eomma

2005 Memoria de mis putas tristes. Trad. Byeong-sun Song, Mineumsa

2007 Vivir para contarla. Trad. Gu-ho Cho, Mineumsa

\section{Borges, Jorge Luis}

1980 Siete noches. Trad. Byeong-sun Song, Hyundae Munhak

1992 La biblioteca de Babel. Trad. Chun-jin Kim, Geul

1994 Ficciones. Trad. Byung-ha Hwang, Mineumsa

1994 Historia universal de la infamia. Trad. Byung-ha Hwang, Mineumsa

2011 . Trad. Byeong-sun Song, Mineumsa

1995 El libro de arena. Trad. Byeong-sun Song, Yemun

1996 El aleph. Trad. Byung-ha Hwang, Mineumsa

2012 _. Trad. Byeong-sun Song, Mineumsa

1996 El informe de Brodie. Trad. Byung-ha Hwang, Mineumsa

1997 La memoria de Shakespeare. Trad. Byung-ha Hwang, Mineumsa

1999 Fervor en Buenos Aires. Trad. Suk-gyun Woo, Mineumsa

2005 Seis problemas para don Isidro Parodi. Trad. Young-joo Kwon, Book House 2008 Otras inquisiciones. Trad. Kyung-won Chung, Yeollin Chaekdeul

\section{Neruda, Pablo}

1989 Veinte poemas de amor y una canción desesperada. Trad. Hyun-jong Chung, Mineumsa

1992 . Trad. Won-hun Choo,

Chungha

1994 Memoirs. Trad. In-wung Yoon, Nokdu

1995 Fábula de la sirena y los borrachos. Trad. Hyeon-kyun Kim, Mineumsa

2000 Oda frente a la isla de Ceylan. Trad. Hye-sun Ko, Munhakgwa Jisung

2002 Cien sonetos de amor. Trad. Hyun-jong Chung, Munhak Dongne 
2008 Confieso que he vivido. Trad. Byung-gyu Park, Mineumsa 2013 Libro de las preguntas. Trad. Hyun-jong Chung, Munhak Dongne

\author{
Allende, Isabel \\ 1991 Eva Luna. Trad. Byung-ha Hwang, Hangilsa \\ 1991 La casa de los espíritus. Trad. Seung-ja Choi, Dungji \\ 1993 \\ . Trad. Gyung-wuk Kim, Sangwon \\ 1993 \\ . Trad. Young-jo Park, Changhyun Munhwasa \\ 2003 \\ Trad. Mi-sun Kwon, Mineumsa \\ 2000 Paula. Trad.Mi-sun Kwon, Mineumsa \\ 2003 La ciudad de las bestias. Trad. Suk-gyun Woo, Biryongso \\ 2005 El reino del dragón de oro. Trad. Mi-sun Kwon, Biryongso \\ 2005 El Zorro: comienza la leyenda. Trad. Mi-sun Kwon, Mineumsa \\ 2005 Retrato en sepia. Trad. Young-sil Cho, Mineumsa \\ 2006 El bosque de los pigmeos. Trad. Mi-sun Kwon, Biryongso \\ 2007 Hija de la fortuna. Trad. Mi-sun Kwon, Mineumsa \\ 2011 La suma de los días. Trad. Mi-sun Kwon, Mineumsa
}

\title{
Arlt, Roberto
}

2008 Los siete locos. Trad. Ji-young Eom, Ungjin Think Big

\section{Asturias, Miguel Ángel}

1981 El señor presidente. Trad. Tae-kyung Park, Pulbit

2012 . Trad. Sang-gi Song, Eulyu Munhwasa

2005 El hombre que lo tenía todo. Trad. Byeong-sun Song, Munhak Sucheop

Bayly, Jaime

2007 Y de repente, un ángel. Trad. In-kyung Ko, Sol

\section{Bioy Casares, Adolfo}

2003 Una muñeca rusa. Trad. Young-ok Ahn, Munhakgwa Jisung

2008 La invención de Morel. Trad. Byeong-sun Song, Mineumsa

\section{Bolaño, Roberto}

2009 La literatura nazi en América. Trad. Hyeon-gyun Kim, Eulyu Munhwasa

2010 Trad. Mi-sun Kwon, Yeollin Chaekdeul

2010 Amuleto. Trad. Hyeon-gyun Kim, Yeollin Chaekdeul

2012 Los detectives salvajes. Trad. Sukgyun Woo, Yeollin Chaekdeul 2010 Llamadas telefónicas. Trad. Se-hyung Park, Yeollin Chaekdeul 2010 Nocturno de Chile. Trad. Suk-gyun Woo, Yeollin Chaekdeul 2013 El gaucho insufrible. Trad. Kyung-min Lee, Yeollin Chakdeul 2013 El tercer Reich. Trad. Kyung-min Lee, Yeollin Chaekddeul 
2013 Monsieur Pain. Trad. Jin-hee Nam, Yeollin Chaekdeul 2013 2666. Trad. Byeong-sun Song, Yeollin Chaekdeul

\section{Cardenal, Ernesto}

1977 Vida en el amor. Trad. Young-moo Kim, Ed. Bundo

\section{Cortázar, Julio}

1985 Colección de cuentos de Cortázar. Trad. Yong-tae Min, Beomjosa 2011 Discurso del oso. Trad. Jin-hee Nam, Salim Eorini

\section{Darío, Rubén}

2012 Obras completas. 1: Poesía. Trad. Hyeon-gyun Kim, Geulnurim

\section{Donoso, José}

1988 Casa de campo. Trad. Chang-hwan Kim, Jihaksa

2009 El lugar sin límites. Trad. Sang-won Lee, Jimanji

\section{Esquivel, Laura}

2001 La ley del amor. Trad. Mi-sun Kwon, Minuemsa

2004 Como agua para chocolate. Trad. Mi-sun Kwon, Minuemsa

2011 Malinche. Trad. Gu-ho Cho, Ed. Sodam

\section{Fuentes, Carlos}

1987 La muerte de Artemio Cruz. Trad. Chang-hwan Kim, Jihaksa 1991 Gringo Viejo. Trad. Sung-ho Chung, Oneul

1994 Aura. Trad. Yong-jae Min, Kimyoungsa

2009 _.Trad. Sang-gi Song, Mineumsa

1996 Diana o la cazadora solitaria. Trad. Chang-min Kim, Jajak Namu

1996 La nueva novela hispanoamericana. Trad. Hyo-suk Chung, Ed. Munwon

1997 El espejo enterrado. Trad. Sung-chul Seo, Kachi

2010 La voluntad y la fortuna. Trad. Hyun-chul Kim, Mineumsa

2010 Todas las familias felices. Trad. Kyung-joo Kim y otro, Ungjin Munhak Edition Pul

2013 Vlad. Trad. Hyun-chul Kim, Mineumsa

\section{Gelman, Juan}

2012 Un pájaro vivía en mí. Trad. Cho-rim Sung, Munhakeui Sup

\section{Mutis, Álvaro}

2000 Diario de Lecumberri. Trad. Byeong-il Choi, Saemi

2010 La nieve del almirante. Trad. Byeong-sun Song, Munhak Dongne 


\section{Onetti, Juan Carlos}

2008 Los adioses. Trad. Hyeon-gyun Kim, Changbi

\section{Pacheco, José Emilio}

1993 Morirás lejos. Trad. Hyun-chul Kim, Nokjin

\section{Padilla, Ignacio}

2006 Amphitryon. Trad. Gu-ho Cho, Changbi

\section{Parra, Nicanor}

1995 Antología poética. Trad. Tae-jin Kang, Sol

\section{Paz, Octavio}

1990 El laberinto de la soledad. Trad. Gwan-su Son, Sinwon Munhwasa 2011 Trad. Eu-seung Hwang y otro. Sechang Media

1995 La otra voz. Poesía y fin de siglo. Trad. Ho-byung Yoon, Hyundae Mihaksa 1996 La llama doble. Trad. Byung-ha Hwang, Ire 1998 El arco y la lira. Trad. Hong-geun Kim, Sol 1999 Los hijos del limo. Trad. Eun-jung Kim, Sol

\section{Piglia, Ricardo}

2010 Respiración artificial. Trad. Ji-young Eom, Munhak Dongne

\section{Pitol, Sergio}

2007 El desfile del amor. Trad. Gi-sun Jeon, Ed. Park Youngryul

\section{Poniatowska, Elena}

2008 La piel del cielo. Trad. In-suk Choo, Munhakgwa Jisung

\section{Puig, Manuel}

2000 El beso de la mujer araña. Trad. Byeong-sun Song, Mineumsa 2004 Boquitas pintadas. Trad. Byeong-sun Song, Chaeksesang 2005 The Buenos Aires Affair. Trad. Byeong-sun Song, Hyundae Munhak 2008 Pubis angelical. Trad. Byeong-sun Song, Eulyu Munhwasa

\section{Roa Bastos, Augusto}

1994 Hijo de hombre. Trad. Jin-hee Nam, Dongsungdong

\section{Sabato, Ernesto}

1988 Sobre héroes y tumbas. Trad. Sun-gyung Chang, Jihaksa 2006 El túnel. Trad. Gu-ho Cho, Irum 


\section{Sepúlveda, Luis}

1993 Un viejo que leía novelas de amor. Trad. Jae-hyung Lee, Yeha

2001 . Trad. Chang Chung, Yeollin Chaekdeul

1995 Mundo del fin del mundo. Trad. Hyung-gang Woo, Sia

2003 . Trad. Chang Chung, Yeollin Chaekdeul

2000 Historia de una gaviota y el gato que le enseñó a volar. Trad. Wang-mu Yoo, Ed. Bada

2001 Diario de un killer sentimental seguido de Yacaré. Trad. Chang Chung, Yeollin Chaekdeul

2001 Nombre de torero. Trad. Chang Chung, Yeollin Chaekdeul

2003 Patagonia Express. Trad. Chang Chung, Yeollin Chaekdeul

2004 Desencuentros. Trad. Mi-sun Kwon, Yeollin Chaekdeul

2005 Historias marginales. Trad. Mi-sun Kwon, Yeollin Chaekdeul

2005 Hot line. Trad. Mi-sun Kwon, Yeollin Chaekdeul

2007 Los peores cuentos de los hermanos Grim. Trad. Mi-sun Kwon, Yeollin Chaekdeul

2010 La lámpara de Aladino. Trad. Mi-sun Kwon, Yeollin Chaekdeul

2012 La sombra de lo que fuimos. Trad. Ji-young Eom, Yeollin Chaekdeul

2012 Historias de aquí y de allá. Trad. Ji-young Eom,, Yeollin Chaekdeul

\section{Skármeta, Antonio}

1996 Ardiente paciencia (El cartero de Neruda). Trad. Mi-sun Kwon, Saramgwa Chaek

2004 . Trad. Wuk-gyun Woo, Mineumsa

2003 La composición. Trad. Ae-kyung Seo, Aiseum

2006 El baile de la Victoria. Trad. Eui-suk Kim, Munhak Dongne

\section{Valenzuela, Luisa}

1999 Tango. Trad. Byeong-sun Song, Munhakgwa Jisung

2010 Realidad nacional desde la cama. Trad. Hye-jin Cho y otros, Ed. Somyung

\section{Vallejo, César}

1995 Piedra negra sobre una piedra blanca. Trad. Yong-tae Min, Koryeowon 1998 Voy a hablar de la esperanza. Trad. Hye-sun Ko, Munhakgwa Jisung

\section{Vargas Llosa, Mario}

1986 La casa verde. Trad. Sun-young Chang, Jihaksa

1991 ¿Quién mató a Palomino Molero?. Trad. Gi-sun Jeon, Mihaksa

1994 Elogio de la madrastra. Trad. Dong-chang Chung, Yeollin Sesang

2010 . Trad. Byeong-sun Song, Munhak Dongne

1995 La historia secreta de una novela. Trad. Hyo-suk Chung, Ed. Munwon 
1998 La señorita de Tacna. Trad. Jun-sik Yoon, Yeni 2002 La tía Julia y el escribidor. Trad. Bo-suk Hwang, Munhak Dongne 2003 La guerra del fin del mundo. Trad. Hyun-chul Kim, Saemulgyul 2004 Los cuadernos de don Rigoberto. Trad. Hyun-chul Kim, Saemulgyul 2005 Cartas a un joven novelista. Trad. Hyun-chul Kim, Saemulgyul 2009 Pantaleón y las visitadoras. Trad. Byeong-sun Song, Munhak Dongne 2010 El paraiso en la otra esquina. Trad. Hyun-chul Kim, Saemulgyul 2010 La fiesta del chivo. Trad. Byeong-sun Song, Munhak Dongne 2011 Travesuras de la niña mala. Trad. Byeong-sun Song, Munhak Dongne

Volpi, Jorge

2006 En busca de Klingsor. Trad. Gyu-ho Park, Deulnyuk

2014 No será la tierra. Trad. Hye-jin Cho, Chungwoneui Chaek 